Liscurso pronunciado por el Catedrático de Historia de la Música, Dr. César Arróspide de la Flor, en la actuación realizada en la Facultad de Letras para conmemorar el segundo centenario de la muerte de Juan Sebastián Bach.

Señor Director del Instituto de Arte,

Señores Catedráticos,

Señoras, Señores:

No resulta hoy extraño encontrar el nombre de Juan Sebastián Bach insertado en un juicio tan concluyente como el de Hendrik van Loon al decir que "es el áltimo de los grandes músicos de la Edad Media" (1). Sin embargo, no es menos cierto que las interpretaciones más frecuentes de la musocolgía le asignan otro significado histórico al llamario "padre de la música moderna". Con argumentos de indiscutible solidez, se le juzga, unas veces, "la más alta personificación del genio del Renacimiento" (2); o "tenazmente adherido al mundo íntimo más popular que literario, del tmisticisme alemán posterior a Lutero" (3); - como llevando la época del cearrrecö Guan dié fisonomía a la Europa del siglo XVII y comienzos del XVIII, "a una eminente culminación y a un final terminante" (4) en su aspecto musical.

No obstante esla aparente disparidad, no es difícil descubrir la unidad subyacente de todos estos juicios, que afirman con acierto distintas facetas de una obra inconmensurablemente rica, en cuyo hondo valor humano, y por tanto social, encuentran su armonía y justa proporción. Aún el que pudiera parecer más osado, al atribuírle la expresión reiterada del espíritu medioeval, puede ser admitido como presumiblemente justo, por más que no se le sustente sino en los signos exte-

(1) Hendrik van Loon.- Histoire des Arts.

(2) J. Combarieu.- Histoire de la Musique.

(3) Federico Sopeña.- Historia de la Música.

(4) Hugo Loichtentritt.- Mísica, Historia o Ideas. 
riores de las formas contrapuntísticas, sin vislumbrar algo más proíun. do por debajo de tal coincidencia o supervivencia estructurel y $\sin$ percibir si acaso de algún modo incide en el problema crucial de la espiritualidad en crisis de nuestra epoca.

*

Padecemos, en estos años, los punzantes desqarramientos de lo que dramáticamente se ha llamado "una cultura sin esperanza". La cjuerra $\sin$ treguas que, cruenta 0 incruentamente, le ha tocado vivir a las generaciones presentes, es el signo de un quebrantamiento intimo que ha conmovido hasta el fondo la sociedad humana. Padecernos la culminación de un proceso cesintegrador que tiene sus raíces en el Renacimiento y glio, progresivamente, ha perturbado el libre juego de las poiencias creadoras del hombre, al romper su trabazón orgánica y su auténtica jerarquia, precipitándolo a una pavorosa soledad, que parece negar la esencia comunitaria de su naturaleza.

La gravitación sccial, que irrenunciablemente àlienta en el fondo del alma humana, reaccionó ya, angustiadamente, hacia formas de solidaridad gue la redimieran de su aislamiento. "El sociologismo extremo - dice Berdiaeff-consituye justamente el reverso del profundo apartamiento y de la gran soledad del hombre. Los átomos separados en el interior tiendenl. Wunirse exteriormente. El Sociologismo extremo, en su acepción filoślicą pracesinmás quevel sotro aspecto del individualismo extremo, de la átomización de la sociedad humana" (5).

El "retorno a la Edad Media", que se propugnó en el esflierzo y la admonición de muchos intelectuailes a raíz de la Gran Guerra del 14, respondió, en cambio, a una aspiración social más profunda. Fué el vislumbre de un nuevo orden posible, de índole fundamentalmente comuniaria, semejante al que precedió al Renacimiento. Fué sobre todo la unidad interna, el sentido orgánico y la visión trascendental, que daban su fisonomía esencial a la Edad Media, los caracteres' que más poderosamente subyugaron las menies de una generación herida por las consecuencias de la atomización y el materialismo triunfantes.

Por esos mismos años de post-guerra, en los dominios musicales, la nueva generación de compositores abdicaba de todo mensaje individual en la obra de arte para cargar el acento en lo objetivo, produ-

(5) Nicclás Berdiaeff.- Una Nueva Edad Media. 
ciendo un consecuente viraje hacia una concepción clásica o intelectual y disipando el clima emotivo y vagoroso del impresionismo debussysta vigente entonces. Esta fué la razón de otro "retorno", el "retorno a Bach", que llevaba en el fondo, insospechada de sus propios gestores, la misma aspiración a un régimen de unidad orgánica y a la restauración de una potente vigencia del espíritu en un arte demasiado prisionero de la sensación y la afectividad. "Hacia 1925 - dice Henry Prunieres-- mientras Schönberg ejerce una influencia inmensa sobre la escuela germánica y transforma el estilo musical, Igor Strawinsky fascina a los músicos latinos y eslavos. Bajo la influencia combinada del cubismo de Picasso y de las teorías poéticas de Paul Valery, va a tentar una nueva serie de experiencias. Cree en la música pura, que no debe consistir sino en una sabia arquitectura y en el empleo de una materia sonora perfectamente adecuada a la forma, sin ingerencia de ideas literarias, de imágenes pictóricas, ni de sentimientos. Es la doctrina reinante de la separación de las artes, a las que el Romanticismo se había esforzado por conjugar. Bach es consagrado el ídolo de esta nueva religión y ni Strawinsky, ni sus discípulos, sabían que su obra, nutrida de símbolos, es la expersión de su fé religiosa. Se decidió que el viejo maestro, no había jamás soñado en otra cosa que en combinaciones abstractas de líneas sonoras y que se le debía imitar"Bổ).

Esta búsqueda de fórmulas para un neo-clasicismo no podía tener arraigo, porque no era allí precisamente donde estaba la actualidad de Bach. En cambio, su vigencia como inspirador, no ya de una realización concreta del arte, cuanto de una actitud espiritual profunda, se mantiene hasta nuestros días. Es que su genio encarna la aspiración actual a una comunidad orgánica, viva y abierta a sus prespectivas trascendentes, que él fué el último en vivir $\mathrm{Y}$ expresar plenamente. $Y$ es tanto más efectiva esta vigencia cuanto que esa expresión fué lograda en el lenguaje que definió y consolidó "el padre de la música moderna" y que ha constituído el cimiento de toda la obra musical de estos últimos siglos.

Ahora bien. como esa concepción eminentemente religiosa y comunitaria, había logrado en la Edad Media una de sus más claras realizaciones, Bach aparece, en lo fundamental de su mentalidad, como un hombre de la cristinadad Medioeval, el último en quien alentaba un

(6) Henry Prunieres.- Les Tendances actuelles de la Músique (La Revue Musicale.janv., 1936). 
espiritu que había sứrido ya profundo cisbranto en fos co:rienzos del siglo XVIII y que supervivia como milayrosanente en cl, en medio de fuerzas decicidamente aciversas.

Esta posición conclusiva de Bach, ha sido percibida reitoradımente por sus bićgráfos. Schweitzer, uno de los que más penetrantemente ha estudiado su vida y su obra, dice: "Bach es un final, un término. Nada parte de él, todo conduce a él. Escribir la verdadera bictrafiz de este maestro, significaría historiar la vida $y$ el decarrollo del arte alemán, gue en él culmina y se acota; comprendiéndo'o al mismo tiempo, en sus tendencias y en sus errores" (7).

Pcr eso, no es de extrañar que ya sus contemporáneos, en quienes las nuevas corrientes del pensamiento moderno habían hecho su camino hacia una mentalidad cada yez más agudizadamente inclividualista, pertenecieran a un horizonte mental totalmente a;eno $y$ distante "El murdo musical de su tiempo --dice Charles Neff-_ encadenado por los suaves acentos de la escuela napolitana (de ćpera) no le prestó atencićn y no comprendió su genio" (8). Ciertamente, se admiró en él sólo al "viruoso"l deĺlórgano Q, Len susSobras, upenas al habilísimo urdidor de complicadas tramas contraguntísticas. En un juicio aparecido en 1737, Lodavía en vida Bach, dice Juan Adolfo Scheibe (citado por Erwin Leuchter en su obra sobre el compositor): "Este gran hombre pcdría despertar la admiración de naciones enteras si poseyera más placidez y si no privara a sus cbras de lo natural, por su carácter ampuloso y confuso, y no ensombreciera su belleza con excesivo artificio. Pretende que toda,s las voces subsistan juntas y con idéntico peso, de modo que no se reconozca entre ellas ninguna principal. La ampulosidad lo ha hecho caer de lo natural a lo artificioso, de lo sublime a lo oscuro y sólo se admira en él su laborioso trabajo y su extraordinario afán, gastado en vano, por desgracia, pues contradice la Razón".

Esto explica porqué Bach no ejerció casi ninguna influencia sobre sus contemporáneos $\mathrm{Y}$ porqué sus obras - salvo el Clave bien Templado y alsunos notetes- quedaron inéditas, escritas de su propia mano y muchàs están perdidas hoy. A raíz de su muerte-según la enu-

(7) Alberl Schwailzer.- J. S. Bach. 
meación publicada por un diario de Leipzig - entre los diez mejores músicss, exclusivamente de Alemania, el nombre de Bach aparece sólo e:a el sétimo lugar. Sabido es que Juan Christian Bach - el menor de sus hijos - llamaloa frecuentemento a su padre "vieja peluca" para significar. cue pertenecía a un arte y a una mentalidad ya superados.

I.a gene:ación inmediata al maestro, pues, ve triunfar el proceso de las corrienies renacentistas en Alemania, donde se habían levantado antes duras resistencias a su penetración. La exigencia de "lo natiral" consignada en la crílica coetanea a Bach, antes trauscrita, reve la el avance humanista orientado a las expresiones cada vez más personnlez; que hacían imposible la vigencia de un arte de indole plenamente comuniataria y supraindividual. "Bach —dice Leuchter- hijo carnal de! espiritu ezlasiáslico, cura obra suprāpersonal estaba enteramente al servicio de la Iolesia, debía ser extraño a una épcca que prociamaba "lo humano" y "lo subjelivo" (9). Y Scheitzer, incidiendo en el mismo rasgo esencial, atima: "Este genio no es individual, sino que, más allá de este límite, tolaliza algo supraindividual, siglos enters, generaciones enteras, han trabalado en la cbra ante clya magnitud nos detenemos con veneración" (10).

\section{Biblioteca Letras}

Ese procesc "de grevitacisin Ellibietprista rabia significado, en el orden de las estructuras sociales, el quebrantamiento de una organizacion eminentemente jerárquica, realizada por la Cristiandad Medioeval, y el advenimiento de una orientación cada vez más decididamente incilvidualista, aporiadä por el Renacimiento. La Reforma transpone esta orienlación a! campo religicso; desvinculondo al creyente de una autoridad ecuménica y afirmando el libre examen, que conducira a la multipiicacićn de sectas. En el dominio estético, asi mismo, contra la expresión eminentemente obejtiva y comunitaria de la Edad Media, reaccionará un arte cue, crecientemente, se tornará en los Tiempos Modernos, expresión de vida y sentimientos porsonales.

Raíz de esta transformación fué el desplazamiento del centro de gravedad cultural, de la concepción teocéntrica de la vida, en que la

(8) Charles Nof- - Mústoire de la Missique.

(9) Ezwin Leusinter- Bach.

(I0) Albert Scheitzer- Ob. cit. 
idea de Dios penetraja todos los pensamientos y actividades del hombre, a la concepción antropocéntrica, cuyo eje es el hombre mismo, a quien da un nievo ángulo de mira, cada vez mús exclusivamente temporal y terreno, para conternplar y comprender el Universo. Tal transformación ha de traducirse, para el valor estético, en la suplantación de un gran aiste de sentido fundamentalmente religioso - el arte medioeval - por un arte siempre más definidamente profano y laico -el del Renacimiento- hasta el de nuestros días

En esta nueva erá fué concentrántiose, a través de todas las exaltaciones y experiencias propias de un movimiento renovader, una comprensión inédita de la función creadora del artista. Este va a quedar día a día más acentuz Jamento contrapuesto a la sociedad, dentro de la oue se yerọre como un caso de excepción. La tradición medioeval en cambio, lo había entendido, instintivamente, como un persont?ro de la comunidad. Esta se expresaba, en su vivencia estética, a través de él, que había recibido la "virtud de arte" y era, por tanto apto para cumplir esa misión. Corno el -artista- otros -teólogos, filósolos, juristas, políticos, comerciantes, etc. - hasta los que llenaban las más humildes profesiones $Y$ menesteres propios de la convivencia humana, servian una función ủlib yodet misno destrino comunitario. En el fondo era la dignificación depunaifran artesanía de raíz profundamente espiritual, que floreció casi siempre en el anonimato y que no reclamaba el tributo de admiración a la persona. Esta, solidaria en el gremio, el burgo, y la soziedad toda, no se sentía dueño exclusiva de la obra, ni le interesaba vincularla a su nombre, como orgulloso exponente de su excepcoinal capacidad.

$$
\text { * }
$$

En Bach descubrimos esa virtud comunitaria latente, con caracteres del todo semejantes que en los viejos artesanos medioevales. "Bach -dice Federico Zopeña- es el último músico que, noblemente, perpetúa la tradisión artesana de los grandes artistas del Medioevo". En él se corona y se ennoblece esa tarea silenciosa, atenta al menor detalle, al servicic siempre de un menester cotidiano, que caracterizó a la artesanía" (11). Podría decirse, sin embargo, que esa tradición su-

(11) Federico Sopeña.- Ob. cit. 
pervive en parte en la de los músicos-funcionarios que mantuvo hata fines del siglo XVIII la aristocracia europea. Pero, ciertamente con Bach concluye el espíritu plenamente comunitario de esos humildes trabajadores de los antiguos gremios. Como ellos, así mismo conoció a fondo su oficio, poseyó una maestría portentosa. "No debemos olvidar - dice Leichtentritt- que la mayor parte de la música de Bach es música de virtuoso del tipo más elevado y puro y requirió para su composición una extraordinaria habilidad en polifonía, harmonía y construcción y para su versión, una habilidad igualmente notable en el canto, dirección y ejecución" (12).

Sin embargo, iqué lejos del exhibicionismo operístico que triunfaba ya en sa época! ¡Cuánta austeridad es menester para acertar con; una jusia interpretación de su música!. La habilidad técnica culmina en la obra de Bach, no para constituir un valor por sí, sino para integrarse al servicio total de un contenido superior, que la justifica $y$ equilibra. Es la misma pericia del tallador medioeval, que cincelaba maravillosamente los perfiles agudos de una aguja gótica, que nadie podría apreciar de cerca, en su exquisito detalle. Con la misma intención de ofrenda y en el mismo anonimato en el cual el artista no se mira a si mismo sino que mira a Dios. "Bach — dice Combarieu- jamás ha tomado una "actitud" como el artista que se sabe mirado y que deseci ser mirado". Jamás ha actuado como personaje en una escena, para una galeriage(13). ccinelli Converso"

Esta espritualidad sencilla y profunda, generosa y humilde, era el fruto de una espontánea visión teo-céntrica de la vida, que se revela en sus hábitos cotidianos, como el de dedicar todos sus trabajos "soli Dei gloriam", según consignaba en sus partituras. En una época en que la gravitación antropocéntrica moderna había polarizado fuertemente los espíritus hacia un norte temporal y terreno, esta mentalidad eminentemente religiosa parece mantenerse dentro de la inspira. ción de la Cristiandad Medioeval.

No obstante, en Juan Sebastián Bach, alentaba la fé de un sincero luterano. Nacido en Eisenach, muy cerca del castillo donde Lutero escribió la versión alemana del Nuevo Testamento, de una larga familia de músicos protestantes: su nombre está definitivamente vinculado al máximo florecimiento de la música litúrgica de su iglesia. Es-

(12) Hugo Leichtentritt.--- Cb. cit.

(13) J. Combarieu.- Ob. cit. 
ta tiene sus mejores exponentes en las Cantatas. Co:alez y Pasones. de Bach; los mejores, pero también los útimss, pues a continuacion de ellos, se señala la decadencia de la música lüerna. Su fororosa adehsićn à la Retorma no entrañó, sin embarco, la aztilud beligorante que dividió a câtólicos y protestantes como consecuencia de las guerras de religión. Párece ser que sa religiosidad no fue porturbada por preocupiciones de secta, como lo reafirma la circunstancia cle haber solicitzdo réteradamente, $y$ en términos de gran sumisión, el título do Compositor de la corte católica de Dresde, para lo que compuso unu de sus obras maestics. la famosa Misa en si menor, scbre e! texto latino destinado al culto de la iglesia romana.

Esta fiscnonía espiritual de Pazh ene ros lo musstra, bajo diversos espectcs, como un último representante de la trudiuín de la Eciad Media, no significa que en él se detenga la evoluzión musical. Por el cortrario, Becin sintetiza esa tradición con todas las conxisias logradas por su arie en los Tiempos Moternos, hasta finalzir la elipa blrroca, que culmina con él. Puede apreciarso esto, en primer término. en lo que rnás calificodargehtececusa espe érmessis: lo esiructura contrapuntística. "Bach recurre a la polifonía hoianciesa - dice I.alchichtritt- y revive una vez mers eze megnifico arter. pero sólo coneitando los rasizos géticos de la polifonía con las concepciones de su propia época, pudo alcinzar un resultado que superaba el simple hecho de rivalizar en habiliciad con los maestros holandeses". Y más adelanie agrega: "En estas gigantescas estructuras renace el arte gótico pero en unz escala más grande y enriquecida con el pinteresco dibujo ornamental que deriva del estilo y gusio barrcco". (14). Sovre todo, se da en él, lo que Paul Bekker llama "la transposición de las formas polifónicas a la esfera de movimientos de la harmonía instrumeatal" (15). La contraposición a la polifonía, que los florentinos habian radicalmente concretado en la melodía acompañada por el sistema de "bajo con tinue", dió a Bacin, al mismo tiempo, un elemento esencial de su sintesis. "El bajo cifrado -explicabo el maestro a sus discípulos de. Leipzig- es el mís perfecto fundamente de la música".

(14) Hugo Leichtentizitl.- Ob. cit.

(15) Paul Eekker.- La Musique. 
A la afirmación del sentido vertical en la simultaneidad sorbra, ya presentida en las grandes obras polifónicas del siglo XVI, se auna la del sentido tonal que Bach va a dejar consolidado. Antes de él, todavía era insegura y confusa la vigencia de los modos nuevos sob:e los antiguos, a juzgar por las polémicas que aun se suscitaban entre alias autoridades sobre esta materia. Cuando la invención de! "temperamentc" para el clave permitió la ejecución y modulación a todas las tonalidades modernas, sin el riesgo de las discrepancias que provocaba la escala natural, Bach ofreció la comprobación práctica de la ventajosa invención, componiendo sus preludios y fugas del Clave bien Templado e impulsando cecisivamenie la vicrencia de esas tonalidades.

Ell triunfo de la concepción armónica, justificada científicamente en sus bases acústicas, estuyo radicalmente vinculada al de la sonoridad instrumental e: la música moderna. A la pura conmprensión de la música como "sonoridad viviente", en la que los instrumentos sólo acompañaban, sostenían o sustituían a la voz, tal como había sido desde la Antigüedad, sucedió la incarporación, como otro gran horizonte de la sensibilidad musizal, de todas las virtualidades de la "sonoridad de lo inerte". A trevés del siglo XVII hace por vez primera su camino un gran movimienio de música instrumental sin precedentes en la historia. Bach asimila toda la herencia de esta gestación radicándola, principalmente, en surgarte de Corganista, ondyas Grispiración penetra al mismo tiempo todas las parcelas de su obra, no sólo instrumental sino aun vocal. Puedo decirse que después de él no se ha loэrado una conquista de trascendencia en la literatưra del órgano, representada e:l forma cimera por sus inmarcesibles obras. Es notoria en el arie de Bach asta influencia del estilo instrumental que alcanza a la melodía cantada, concebida en díseños que a veces fuerzan las posibilidades normales y cómodas de la voz, como es de verse, sobre todo, en sus "arias concertantes" en las que, al flanco de ésta y con semejante importancia, jueọa la melodía de un instrumento "obligato". Tales arias pierden así el cárácier genuinamente vocal a la vez que la expresićn de individualismo excluyente, propio al solo de canto operístico, y acusan una inspiración suprapersonal ajena al arte de teatro.

Esto no obstante y tenida cuenta de que Bach abordó todos los géneros conocidos en su ópoca, salvo la ćpera, sería erróneo considerarlo, totalmente desvinculado de esta expresión tan peculiar y tí- 
pica del arte barroco. Es cierto que nada había tan disiante del espítu de este humilde ariesano. gue entregaba a Dios su tarea cotidiana, como el ostentoso y mundanal espectáculo de la ópera. A pesar de que su época se encontró literalmente inundada por la producción de este género, jamás se le ocurrió abordarlo. Empero, esto no significa que no lo conociera y que no fuera capaz de gczar con él. No solo eso, evidenciando una vez més la integral asimilación por Bach de los valores positivos aportados por su siglo, su obra incorpora el valor dramático personal conquistado por el Renacimiento. $Y$ al hacerlo, penetra su profundo y espiritual sentido, como lo intuyera Monteverdi y lo continuaran los cultivadores de la ópera y el oratorio que locsraron superar la gravitación efectista y decorativa del espíritu cortesano. Basta recordar los "recitativos" de la Basión según San Mateo para comprobar el enorme caudal de emoción dramática de que era capaz su vena creadora.

Vemos así que la obra de Juan Sebastián Bach, es la síntesis de tcdos los valores de su época con la tradición viva anterior. Esta sintesis era la expresión justa de una unidad social que en su tiempo sufría ya serio quebranto, por fos avances de un humanismo desarraigado de sus funciamientos religicisoslyi quen marcaba un proceso de creciente desintegración de esa unidad. Por eso, nuestro tiempo que vive el momento de exacerbaciór de tal proceso, con la carga de todas sus grandezars y miserias, hallazgos positivos y lastres materialistas, siente el anhelo instintivo de una expresión estética semejante a la de Bach, que sea índice de una unidad orgánica y viva, de la que está sediento. La vigencia de su arte se explica, por tantc, porque hoy se padece la ausencia de lo que él significa: el hallazgo de una auténtica solidaridad humana que se viva, sencillamente, en la brega de cada día por cumplir nuestro común destino. 